\title{
A Comparison of Attachment Styles and Identity Styles in People with Gender Dysphoria Disorder (Operated and Not Operated) and Normal People in Southwest of Iran In 2014
}

\author{
Nahid Mahmoodi \\ MSc, Department of Psychology, College of Fars Science and Research, Shiraz Branch, Islamic Azad University, Shiraz, Iran \\ Corresponding Author Email: mahmoodi.n2014@gmail.com \\ Ghasem Naziri \\ Ph.D, Department of Psychology, Shiraz Branch, Islamic Azad University, Shiraz, Iran \\ Email: nazirry@yahoo.com

\section{Mohammad Zarenezhad} \\ MD, Legal Medicine Research Center, Legal Medicine Organization, Tehran, Iran and \\ Member of Gastroentrohephatology Research Center, shiraz University of Medical Sciences, Shiraz, Iran \\ Email: Zarenezhad@Hotmail.com
}

\section{Doi:10.5901/mjss.2015.v6n6s6p381}

\section{Abstract}

The gender dysphoria disorder is a very rare condition and family is a factor relating to that which is probably effective in its etiology and also at the same time, in its retention. The aim of this study was to compare the attachment style and styles of identity in individuals suffering from this disorder and normal individuals in southwest of Iran. This case control study, was performed to 52 patient from the forensics head office of Fars province who have been diagnosed as suffering from gender dysphoria disorder (the case group) and 150 available people who have been cleared by psychologist of any psychological disorder (witness group). The study tolls include demographic data and Revised Adult Attachment Scale (Collins and Read) and identity styles questionnaire (ISI) were used in both groups. The gathered data analyzed with the SPSS software (v.18). The statically method's includes univariate $F$, Scheffè Poc-Hoc test. A level of significance of $(P<0.05)$ was considered. There was seen the significant difference between normal people and people with GID in ambivalent attachment style $(P$ $<0.001)$, (0.01) and there is also significant difference between people of GID who have operated, in secure attachment style ( $P$ $<0.001)$ and Normative Identity Style (0.04) and Character Style Commitment $(P<0.001)$. It can be deducted from the results of this research that there is a reciprocal correlation between attachment style, identity style and GID.

Keywords: Object attachment; Identity; Style; Gender identity; Sexual and gender disorder; Iran.

\section{Introduction}

Gender dysphoria is a psychological condition which is a reflection of the individual's feeling of his or her sexual identity (Besharat et al., 2012), it appears at the age of 18 months and is often consolidate

By the age of 24 to 30 months which is usually coordinated with the individual's anatomic gender ((Yazdanpanah \& Samadian, 2011), (Asgari et al., 2008)). One of the listed disorders in mental disorders diagnostic and statistical guide is the identity dysphoria disorder which will be in the form of the difference between determined gender at birth and the mental impression of belonging to a particular gender ((Vitelli \& Riccardi, 2011), (Hedjazi et al, 2013)). These individuals constantly feel uncomfortable with their biological gender (Hatami \& Ayvazi, 2013), and try to proximate themselves to the opposite sex by use of hormones and operation ((Mehrabi 1996), (Okabe $\mathrm{N}$ et al, 2008)). Usually in patients and individuals suffering from GID, the initial childhood growth, emotional relationship with parents-children ((Spack et al, 2012), (Amani et al, 2012)), and the condition inside family life can create a state which leads to this disorder((Arya et al, 2012), (Momeni javid \& Shoaa kazemi, 2011)).

Attachment is creating a deep emotional relationship with particular individuals. Such a synthesis in individuals, create happiness and joy and leads to individuals comforting one another in times of stress ((Amiri et al, 2013), (Hejazi \& Negahban Selahi, 2009)). The initial interaction between parent-child forms some beliefs in the child about stability, support and response of parents which will become his/her guide in expression of emotions in later life(Sheinbaum et al, 
2015).Einzworth (1987) identified three models of secure attachment, insecure-avoidance, anxious-ambivalent (Verbeke et al, 2014).Individuals with a secure attachment have a sound base from psychological point of view (Talebzadeh Nobarian et al, 2011) and they are comfortable in setting up intimate relationships (Ahadi, 2009), individuals with avoidance attachment are more inclined to avoid intimacy and attachment to others and individuals with ambivalent attachment have a strong tendency to communicate with others, however this tendency is accompanied by the fear of rejection from others (Amiri et al, 2013).

Family is the first environment where the individual learns about the norms and behavioural methods expected of a man or woman, and if the family does not play their role appropriately, children will face problems one of which is GID (Yazdanpanah \& Samadian, 2011). Simon (2011) showed in his research that most people who had MF transsexuality were due to having unsuitable parents (Simon et al, 2011).Other studies have specifically identified family factors effective in creating gender dysphoria disorder, these include: existence of a depressed mother, too much of a close relationship with mother, mother's lack of support and father's absence ((Yazdanpanah \& Samadian, 2011), (Sípová \& Brzek, 1983), (Cohen-Kettenis \& Gooren, 1999), ( Rezaei et al, 2007), (Zucker, 2008)).

One of the basic tasks of growth in adolescence is the acquiring a coherent and lasting identity which affect the individual's determination of worldview, the feeling that "who am I"? , "what is my status in society"? ((Rahimian boger \& Hagh parvar, 2013), (Vahedi \& Zarabi, 2013)). Identity is among the most important and determining issues in life (Teimouri et al, 2013), Erikson (1968) believes that having an appropriate identity is linked to feeling of being accepted by favourite persons (Verbeke et al, 2014).Berzonski (2013) developed the Social-Perception model from the formation of identity which. These include: information styles, normative and confused- avoidance (Berzonsky et al, 2013).People with information style are engaged in the process of active self-probing (Rahimian boger \& Hagh parvar, 2013).People with normative style follow the existing values and that of others (Sargezi \& Nickmanesh, 2013) people with confusedavoidance style are a symbol of evasive encounter with problems (Abdi Zarin et al, 2009). Many researchers, have stated that the level of emotional relation in the family is another factor in formation of identity (Yazdanpanah \& Samadian, 2011), Faber et al, 2003) and an unsuitable family environment leads to a weak self-image in individuals (M A, 2012).

Considering So that gender as the most basic identity element that accompanies the individual throughout their life (Javaheri \& Hosein zadeh, 2011) and the signs of gender dysphoria disorder appear early in the process of transition; it seems that indecision about the initial relation attachment which has an undeniable role in the process of identity formation and appearance of GID, can be important ((Yazdanpanah \& Samadian, 2013), (Okabe et al, 2008 ), (Saber \& Pasha Sharifi, 2013)). Then the present Study Was Performed to Assess the Determine of attachment and identity styles in people with gender dysphoria disorder and normal people in the city of Shiraz.

\section{Materials and Methods}

This study is a sectional control study which includes three statistical populations (A) all TS individuals who were referred to psychiatrist clinics approved by the forensic medical board for clinical evaluation (case group1);(B) all TS individuals in the time range of the last 2 to 10 years who have had a sex change operation and their files were available in Fars Province Forensics Medical Office and their problem was identified by their medical commission (case group 2); (C) normal people (witness group) who were selected from among accessible individuals who according to the psychiatrist, lacked any kind of psychological disorder, by synchronization with the case group in variables such as age, gender, education, employment. After acquiring all the necessary permissions from the office of Fars Province Medical Forensics and consent of the qualified individuals who showed a willingness to take part, sampling was conducted. The sampling method used was Convenience sampling and took four months to complete. The Declaration of Helsinki was observed to safeguard the identity, reputation and medical secrets of the individuals (Spack et al, 2012) and they were assured of the confidentiality of their data and no need of their names and addresses in the research and there is no affect in review and decision making and the results obtained and that they will not be facing any consequence (Rezaei et al, 2007).

Data gathering tools included Revised Adult Attachment Scale (Collins and Read); and identity Style Inventory (ISI) with demographic variables (age, gender, education and employment).

Revised Adult Attachment Scale has 18 clauses of five options in the form of 3 subscales (dependency, affinity and anxiety) (Zucker, 2008) and it used for people of 16 years old or over. Each 6 clauses are related to a subscale, for options 1 to 5 scores 0 to 4 were considered respectively. Average reliability coefficient of this tool was reported at $81 \%$ for affinity subscale, dependency $78 \%$ and $85 \%$ for anxiety subscale (Rahimian boger \& Hagh parvar, 2013). Cronbach alpha coefficients for secure, avoidance and ambivalent subscales for a sample of 30 individuals were obtained as affinity subscale of $88 \%$, dependency subscale $90 \%$ and anxiety subscale $92 \%$. These coefficients show the internal consistency scale very well. Also, the content validity of this questionnaire has been verified by the professional psychologists and 
their consultant and psychometric and modification (Zucker, 2008).

Identity Style Inventory (ISI) was first created by Berzonski to evaluate individuals' identity orientation (Zucker, 2008) and it was revised by White et al. in 1998 (Hejazi \& Negahban Selahi, 2009). This test is a 40 phrasal Self reporting tool made up of 4 subscales which includes information and identity styles (11 questions), normative style(9 questions), confusion-avoidance style(10 questions)and the fourth subscale is the commitment style(10 items) (Vahedi \& Zarabi, 2013). Which is used for secondary analysis and it is not considered as an identity style. Replies are adjusted on the basis of likert scale of 5 degrees which is evaluated on the basis of ranges from: it is not like me at all (Besharat et al, 2012) to it is very much like me ((Hatami \&Ayvazi, 2013), (Abdi Zarin et al, 2009)). A separate score is calculated for each respondent in each of the said scales and the total scores of each individual in each subscale determine the testing identity style (Rahimian boger \& Hagh parvar, 2013). Berzonski (2013) introduces four factors in present questionnaire on the basis of exploratory factor analysis which includes the following items: information identity style, normative identity style, confusion-avoidance identity style and commitment style (Vahedi \& Zarabi, 2013). It is worth mentioning that phrases 9, 11, 14 and 20 are scored in a reverse fashion (Rahimian boger \& Hagh parvar, 2013). In hejazi, Farsi Nejad and Askari's study, Cronbach Alpha was reported $77 \%$ for information identity style, $60 \%$ for normative identity style, $66 \%$ for confusion-avoidance identity style and $68 \%$ for identity commitment (Hejazi \& Negahban, 2009). Using theand descriptive statistical method (mean, standard deviation, frequency, percent) and analytic statistic (parametric tests of $\mathrm{F}$ univariate test, scheffè poc-Hoc test) and SPSS software (version18) the data was analyzed and in this Study, the cronbach alpha was considered at 0.7 and significance level was considered at $(P<0.05)$.

\section{Results}

According to present study's findings, 202 individuals in total entered the study who, suffered from gender dysphoria disorder and included 27(51.9\%), operated 25(49.1\%) not operated and 150 normal individuals. In this study, the mean age of participants with ID (operated and not operated) was $24.29 \pm 3.935,15$ individuals MF, 37 individuals FM, the highest frequency in education level were national diploma 15 and regarding employment, Self- Employment with 20 individuals .Also, the mean age of the normal people was $29.36 \pm 9.168$ the highest frequency of educational level was national diploma 33 persons, and employment position was Self Employment 57 persons (table 1).

Table 1: Demographic variables in 3 groups $^{1}$

\begin{tabular}{|l|l|c|c|c|}
\hline Demographic Variables & & GID people (operated) & $\begin{array}{c}\text { GID people } \\
\text { (not operated) }\end{array}$ & Normal people \\
\hline \multirow{4}{*}{ Age } & Age range & $19-36$ & $18-28$ & $18-65$ \\
\cline { 2 - 5 } & $\overline{\boldsymbol{X}}$ & 25.41 & 23.08 & 29.36 \\
\cline { 2 - 5 } & S.D & 4.627 & 3.252 & 9.168 \\
\hline \multirow{5}{*}{ Eender } & Male & $19(\% 70.4)$ & $7(\% 28)$ & $71(\% 47.3)$ \\
\cline { 2 - 5 } & Female & $8(\% 29.6)$ & $18(\% 72)$ & $79(\% 52.8)$ \\
\hline \multirow{5}{*}{ Education } & Unemployed & $5(\% 18.5)$ & $12(\% 48)$ & $29(\% 19.3)$ \\
\cline { 2 - 5 } & Pupil & $0(\% 0)$ & $3(\% 12)$ & $3(\% 2)$ \\
\cline { 2 - 5 } & Student & $1(\% 3.7)$ & $2(\% 8)$ & $21(\% 14)$ \\
\cline { 2 - 5 } & Self employed & $20(\% 74.1)$ & $8(\% 32)$ & $69(\% 46)$ \\
\cline { 2 - 5 } & Employee & $1(\% 3.7)$ & $0(\% 0)$ & $28(\% 18.6)$ \\
\hline & Below Diploma & $4(\% 14.8)$ & $3(\% 12)$ & $9(\% 6)$ \\
\cline { 2 - 5 } & Diploma & $9(33.3 \%)$ & $6(\% 24)$ & $17(\% 11.3)$ \\
\cline { 2 - 5 } & Higher National Diploma & $2(\% 7.4)$ & $3(\% 12)$ & $11(\% 7.3)$ \\
\cline { 2 - 5 } & Bachelor & $5(\% 18.5)$ & $6(\% 24)$ & $33(\% 22)$ \\
\cline { 2 - 5 } & Masters & $4(\% 14.8)$ & $1(\% 4)$ & $23(\% 15.3)$ \\
\cline { 2 - 5 } & PhD & $1(\% 3.7)$ & $0(\% 0)$ & $0(\% 0)$ \\
\cline { 2 - 5 } & Student & $2(\% 7.4)$ & $6(\% 24)$ & $57(\% 38)$ \\
\cline { 2 - 5 } & Total & $27(\% 100)$ & $25(\% 100)$ & $150(\% 100)$ \\
\hline
\end{tabular}

Analysis of variance of 3 groups in attachment styles, shows that groups in secure and ambivalent attachment styles have a significant difference $(P<0.001)$, and groups in avoidance attachment styles, do not have a significant difference

1. Demographic variables in 3 groups of GID patients operated, not operated and normal people 
$(P=0.481)$. But analysis of variance in the 3 groups in identity styles shows that there is significant difference in commitment identity style with $(P<0.001)$ and normative identity style with $(P=0.042)$ in groups and no significant difference exist between groups in avoidance identity style with $(P=0.628)$ and information identity style with $(P=0.217)$. Considering the significance of groups effect and lack of equal number of samples in the 3 groups for specifying different groups, scheffè Poc-Hoc test was used which is more creditable for unequal samples as follow.

In this study, a significant difference was observed between normal people and people with GID (both operated and not operated) in ambivalent attachment style $(P<0.001),(0.01)$, and there was also significant difference between in secure attachment $(P<0.001)$ and normative identity $(0.04)$ and commitment identity style $(0.00)$. Furthermore, a significant difference was observed between People with gender dysphoria disorder Who have or not operated in ambivalent attachment style (0.04) and commitment identity style (0.00) but there was no significant difference in other cases $(P<0.05)$ (tables $2 \& 3)$.

Table 2: multi-comparison of 3 groups in attachment style ${ }^{2}$

\begin{tabular}{|c|c|c|c|c|c|c|c|}
\hline \multirow{2}{*}{$\begin{array}{l}\text { Dependent } \\
\text { Variable }\end{array}$} & \multicolumn{2}{|c|}{ Group type } & \multirow{2}{*}{$\begin{array}{l}\text { Average difference } \\
\qquad(j-1)\end{array}$} & \multirow{2}{*}{ S.D.E. } & \multirow{2}{*}{ Sig. } & \multicolumn{2}{|c|}{$\begin{array}{c}\text { 95\% Significance } \\
\text { level }\end{array}$} \\
\hline & $\begin{array}{c}1 \\
\text { (operation) }\end{array}$ & $\begin{array}{c}\mathrm{J} \\
\text { (operation) }\end{array}$ & & & & $\begin{array}{l}\text { Lower } \\
\text { than }\end{array}$ & $\begin{array}{c}\text { Higher } \\
\text { than }\end{array}$ \\
\hline \multirow{3}{*}{$\begin{array}{l}\text { Secure } \\
\text { Attachment }\end{array}$} & Operated & Not operated & -1.58 & 0.693 & 0.08 & 3.29 & 0.12 \\
\hline & Operated & Normal & $2.74 *_{-}$ & 0.521 & $<0.001$ & $4.02-$ & $1.45-$ \\
\hline & Normal & Not operated & 1.16 & 0.529 & 0.09 & $0.15-$ & 2.46 \\
\hline \multirow{3}{*}{$\begin{array}{l}\text { Avoidant } \\
\text { attachment }\end{array}$} & Operated & Not operated & $0.37-$ & 0.891 & 0.919 & $2.56-$ & 1.83 \\
\hline & Operated & Normal & $0.81-$ & 0.671 & 0.481 & -2.46 & 0.84 \\
\hline & Normal & Not operated & 0.45 & 0.680 & 0.807 & -1.23 & 2.12 \\
\hline \multirow{3}{*}{$\begin{array}{l}\text { Ambivalent } \\
\text { attachment }\end{array}$} & Operated & Not operated & $3.78^{*}$ & 1.448 & 0.04 & $0.21-$ & 7.34 \\
\hline & Operated & Normal & 3.37 & 1.090 & $<0.001$ & 4.68 & 10.05 \\
\hline & Normal & Not operated & $3.59 *_{-}$ & 1.106 & 0.01 & 6.31- & $0.87-$ \\
\hline
\end{tabular}

Table 3: multi-comparison of 3 groups in identity styles ${ }^{3}$

\begin{tabular}{|c|c|c|c|c|c|c|c|}
\hline \multirow{2}{*}{$\begin{array}{l}\text { Dependent } \\
\text { variable }\end{array}$} & \multicolumn{2}{|c|}{ Group type } & \multirow{2}{*}{$\begin{array}{l}\text { Average difference } \\
\qquad(\mathrm{j}-1)\end{array}$} & \multirow{2}{*}{ S.D.E. } & \multirow{2}{*}{ Sig. } & \multicolumn{2}{|c|}{$\begin{array}{c}95 \% \text { Significance } \\
\text { level }\end{array}$} \\
\hline & $\begin{array}{c}1 \\
\text { (operation) }\end{array}$ & $\begin{array}{c}\mathrm{J} \\
\text { (operation) }\end{array}$ & & & & $\begin{array}{l}\text { Lower } \\
\text { than }\end{array}$ & $\begin{array}{c}\text { Higher } \\
\text { than }\end{array}$ \\
\hline \multirow{3}{*}{$\begin{array}{l}\text { Information } \\
\text { identity }\end{array}$} & Operated & Not operated & -0.20148 & 0.16264 & 0.466 & -0.6026 & 0.1996 \\
\hline & Operated & Normal & -0.21421 & 0.12250 & 0.219 & -0.5163 & 0.0879 \\
\hline & Normal & Not operated & 0.01273 & 0.12659 & 0.995 & -0.2995 & 0.3249 \\
\hline \multirow{3}{*}{$\begin{array}{l}\text { Normative } \\
\text { identity }\end{array}$} & Operated & Not operated & -0.25811 & 0.20177 & 0.443 & -0.7557 & 0.2395 \\
\hline & Operated & Normal & $-0.38033^{\star}$ & 0.15197 & 0.04 & -0.7551 & -0.0055 \\
\hline & Normal & Not operated & 0.12222 & 0.15704 & 0.739 & -0.2651 & 0.5095 \\
\hline \multirow{3}{*}{$\begin{array}{l}\text { Avoidance } \\
\text { identity }\end{array}$} & Operated & Not operated & -0.08993 & 0.16969 & 0.869 & -0.5084 & 0.3286 \\
\hline & Operated & Normal & -0.12259 & 0.12781 & 0.632 & -0.4378 & 0.1926 \\
\hline & Normal & Not operated & 0.03267 & 0.13207 & 0.970 & -0.2931 & 0.3584 \\
\hline \multirow{3}{*}{ Commitment } & Operated & Not operated & $-0.75511^{*}$ & 0.18600 & $<0.001$ & -1.2138 & -0.2964 \\
\hline & Operated & Normal & $-0.78311^{*}$ & 0.14010 & $<0.001$ & -1.1286 & -0.4376 \\
\hline & Normal & Not operated & 0.02800 & 0.14477 & 0.981 & -0.3290 & 0.3850 \\
\hline
\end{tabular}

\section{Discussion}

The findings of this study regarding age variable average of $24.25 \pm 4.028$ in people with gender dysphoria disorder (operated and not operated) are consistent with study of Hejazi (Hedjazi et al, 2013) but they are not consistent with study Noorian (Nourian et al, 2008) whose average age in her study was reported as 26 respectively. The gender variable in the population under study which included 15 male and 37 female (15 MF and 37 FM) are consistent with

2 Results of Scheffè Poc-Hoc Test for multi-comparison of groups in attachment style variable

3. Results of Scheffè Poc-Hoc Test for multi-comparison of groups in identity styles variable 
Hejazi's study (Hedjazi et al, 2013) in the number of MF. However, they are not consistent with Javaheri's study (Javaheri $\&$ kochakian, 2006) where $66 \%$ of the cases of his study were male and $33 \%$ female. The education variable where the majority had ND (30\%) are consistent with Rahim Parvar's study (Vasegh rahimparvar et al, 2013) but not consistent with study Noorian (Nourian et al, 2008) which is made up of $72.5 \%$ of his population of ND.

The employment variable of self- employment (34 - 56.7\%) is consistent with study Hejazi (Hedjazi et al, 2013) but it is not consistent with the number employed persons, which in Javaheri's study (Javaheri \& kochakian, 2006) it was stated at 27\%. The findings of present study are consistent with studies of besharat (Besharat et al, 2012), zucker (Vahedi \& Zarabi, 2013) and Sipova (Sípová \& Brzek, 1983) in that there is significant difference between normal people and people with gender identity disorder (operated and not operated) in ambivalent attachment style $(P<0.001),(0.01)$, and also there is a significant difference between normal people and people with gender identity disorder who have operated in secure attachment style $(P<0.001)$ and there is also a significant difference between people with gender identity disorder who have operated and not operated in ambivalent attachment style(0.04).

Considering that gender identity disorder is an unexpected phenomenon and the person is born with healthy and natural body, the occurrence of opposite gender identity from the age of 2 or 3 years is not predictable and comprehensible for parents. This problem disrupts the acceptance of the child and a sustainable strong emotional relationship with parents, Specially the mother (Besharat et al, 2012) which is consistent Zucker (Teimouri et al, 2013) and Coates's (Taheri et al, 2013) findings which claim that 78\% of mother of children with GID have experienced mental trauma and family problems in the first three years of their child's life and they have often been inaccessible emotionally for the duration. Mothers of such children show signs of insecure child careers. They are often inaccessible, insensitive, nonresponsive and illogical and they neglect their children, lack emotion and are cold, interfering and rejectionist and they cause insecure attachment to form in children, something that has been verified and is consistent with studies ((Berzonsky et al, 2013), (Sargezi \& Nickmanesh, 2013), (Abdi Zarin, 2009)). Appearance of behaviors relating to opposite sex in children who suffer from gender identity disorder intensifies the cold and rejectionist behaviors of the parents. It is therefore logical that most people suffering from gender identity disorder have insecure attachment styles (Besharat et al, 2012). Considering the finding that the highest score for insecure attachment styles among individuals with gender identity disorder relates to ambivalent attachment style, this style of attachment is connected to unpredictability and irregular access of the career and the Features Which According to Previous Studies, exist in these individuals' mothers and the child's fear of career's negative evaluations of himself/herself.

People with ambivalent attachment style have a negative image of themselves, they are monopolist in their emotional relation with others and are dependent (Ahadi et al, 2009), they have a tendency to have relationships with others but this tendency is accompanied by the feeling of being rejected (Amiri et al, 2013), But others do not wish to be as near to these individuals as they wish (Javaheri \& Hosein zadeh, 2011) Which is consistent with the characteristics of people with gender identity disorder and this has been verified by the results of this research.

Insecurity of attachment in children with the biological basis for gender identity disorder can intensify the accession and growth of this disorder. Lack of satisfaction of child's emotional needs, severe experiences of rejection and neglect in childhood and Lack of experiencing a sustained and deep emotional union makes insecure individuals prone to various communication problems and mental disorders (Besharat et al, 2012).

The findings of present study regarding a significant difference between normal people and people with GID who have operated in normative identity style(0.04) and commitment(0.00), can be explained thus: these individuals, considering their relation with others is seriously challenged during the stages of having an operation or even before that when they decide to operate and follow the stages and are usually rejected by their family or friends and are drawn into solitude (Mojiri, 2010), Face the lack of presence of important members of their family in their life after their operation who would be committed to them or the norms acceptable to them and accept them, will naturally be below normal people in their normative identity style.

The findings of present study reflecting that there is a significant difference between people with gender identity disorder who have operated and those who have not in commitment identity style(0.00), can be explained that the sex change operation causes a reduction in identity styles and may be due to individual having to face the real world. Sex change affects peoples' identity and also alters the field of social roles they have to undertake (Faber et al, 2003) but considering the findings, it can be explained that these individuals' identity style undergoes a tangible change in the commitment index. Although attempts to change sex is a complicated situation which has a significant effect on the health and integration of the person's sexual-mental and social life, however, having the operation is not enough for taking on the opposite gender, rather it is necessary for the person to learn the behavior pattern of that sex and others have to accept their new gender (Momeni javid \& Shoaa kazemi, 2011). It is worth mentioning that having searched various sources, no similar study for comparison with this result was found and the recent finding of this study can be a beginning 
for supplementary studies in future.

\section{Conclusions}

It can be deducted that the discontent of the individual with his/her gender is in fact introjections of disgust of being male or female which has been formed in the family relations environment and appears as zooming out of signs of gender identity disorder.We can also consider an interaction between attachment style, identity style and gender dysphoria disorder. Thus, if the emotional relation with family has precedent on appearance of gender dysphoria disorder and has caused this problem, the disorder can itself be effective on maintaining performance of low emotional relation with family or its intensification and naturally effect the individual's future identity style.

Among the limitations of this research, we can point to the difficulty in attracting the trust of GID patients in cooperating, lack of generalization of findings due to use of accessible sampling and selection of samples from one province which makes it difficult to relate these findings to all people with gender identity disorder.

It is recommended for future research, to conduct a longitudinal research in order to compare a person before and after operation and then compared with normal people.

Researcher will hereby acknowledge and appreciate the kind cooperation of Forensic Medicine of the province and all the participants with GID to support this research.

\section{References}

Besharat M; Tavalaeian F; Lavasani MS. Comparison between the attachment styles in patients with gender identity disorder and nonpatients. Scientific journal of forensic medicine. 2012;18(2-3):89-97.

Yazdanpanah I; Samadian F; Survey of gender identity disorder focusing on the role family: comparative study referred to welfare organization kerman. 2011.

Asgari M; Saberi M; Rezaei O; Dolatshahi B; he Prevalence of mental suffering in patients with gender identity disorder. Scientific journal of forensic medicine. 2008;13(3):81-186.

Vitelli R; Riccardi E; Gender identity disorder and attachment theory:The influence of the patient's internal working models on psychotherapeutic engagement and objective. A Study undertaken using the adult attachment interview.International journal of transgenderism. 2011;12:241-53.

Hedjazi A; Zarenezhad M; Hosseini M; Socio-demographic Characteristics of transsexuals Referred to the Forensic Medicine Center in Southwest of Iran.North American Journal of medical sciences. 2013;5(3):224-7.

Hatami M; Ayvazi S; Investigating of personality characteristics (extroversion introversion) and Early Maladaptive Schemas (EMS) in males and females with gender identity disorder (GID). procedia - social and behavioral sciences 2013;84:1474 - 80.

Mehrabi F; The survey some of properties in transforming gender in Iranian patients. Thought and behaviour. 1996;3:4-12.

Okabe N; Sato T; Matsumoto Y; Ido Y, Terada S; Kuroda S; Clinical characteristics of patients with gender identity disorder at a Japanese gender identity disorder clinic.Psychiatry Research. 2008;157:315-8.

Spack N; Leeper L; Henry A; Children and adolescents with gender identity disorder referred to a pediatric medical center. Official journal of the American of pediatrics. 2012;129:418-25.

Amani R; Etemadi O; Fatehi M; Relation between attachment styles and social compatibility. clinical psychology and personality, Shahed University. 2012;19(6):15-26.

Arya A; Tripathi A; Singh H; Kumar P; Gender identity disorder with comorbid depression. Delhi psychiatry journal. 2012;13(1):153-6.

Momeni javid M; Shoaa kazemi M; comparing personality disorder, gender identity and normal. social research journal. 2011;4(13):8194.

Amiri F; Banijamali S; Ahadi $\mathrm{H}$; The relationship between attachment style and self-efficacy beliefs with regard to sex.Pelagia research library. 2013;3(1):699-704.

Hejazi E; Negahban Selahi M; Relation of attachment styles to parents and peers with identity styles in teenagers.Educational science \& Psychology journal. 2009;39(1):107-31.

Sheinbaum T; Kwapil T; Ballespí S; Mitjavila M; Chun C; Silvia P; et al. Attachment style predicts affect, cognitive appraisals, and social functioning in daily life. Frontiers in Psychology. March 2015;6(296):1-10.

Verbeke W; Pozharliev R; VanStrien J; Belschak F; Bagozzi R; I am resting but restless well with you. "The moderating effect of anxious attachment style on alpha power during EEG resting state in a social context. Frontiers in Human Neuroscience. July2014;4(486):1-10.

Talebzadeh Nobarian M, Moussavi H, Radmehr A. Review of relation of attachment styles with emotional intelligence \& exam stress of high school pupils. Research \& family quarterly journal. 2011;10:87-102.

Ahadi B. The relationship between sense of solitude and self-esteem and attachment styles of students. Psychological studies. 2009;5(1):95-112.

Simon L; Zsolt U; Fogd D; Czobor P; Dysfunctional core beliefs, perceived parenting behavior and psychopathology in gender identity disorder; A comparison of male-to-female, female-to-male transsexual and non-transsexual control subjects. Behavior therapy 
and experimental psychiatry. 2011;42:38-45.

Sípová I; Brzek A; Parental and interpersonal relationships of transsexual and masculine and feminine homosexual men.Homosexuals and social roles. 1983:75-85.

Cohen-Kettenis P; Gooren J; Transsexualism: a review of etiology, Diagnosis and treatment, Journal of psychosomatic research. 1999;46:315-33.

Rezaei O; Saberi M; Shahmoradi H; Malek khosravi G; Family functioning in patients with gender identity disorder. Journal of rehabilitation. 2007;8(29):58-63.

Zucker K; Children with gender identity disorder: is there a best practice?Neuro psychiatry del'enfanceet. del'adolescence. 2008: 358-64.

Rahimian boger $\mathrm{E}$; Hagh parvar M; Role of identity styles in prediction of religious orientation of students. Psychological researches. 2013;16(2):27-41.

Vahedi S; Zarabi M; Role of attachment dimensions to parents and cognitive processes in youth identity processing styles.Psychological studies (College of Psychology \& educational sciences, University of al zahra). Autumn2013:9(3):9-28.

Teimouri M; Bagheri F; Farokhi N; The study of self-efficacy relationship with youngster identity style ranging from 18-28 year old in Karaj.European journal of experimental biology. 2013;3(1):690-3.

Berzonsky M; Soenens B; LuyckX K; Development and validation of the revised identity style inventory (ISI-5): Factor structure, reliability and validity.Psychological assessment. 2013;25(3):893-904.

Sargezi M; Nickmanesh Z; Identity styles and religious self determination.Psychology \& Religion. 2013;6(2):91-104.

Abdi Zarin S; Edi berad N; Yonesi j; Identity styles with self- efficiency concept of iranian and afghan high school boys in Qom. The social welfare Scientific \& Research journal. 2009;10(39):445-71.

Faber A; Edwards A; Baure K. Family structure:Its effects of adolescent attachment and identity formation. The american journal of therapy. 2003;31:243-55.

M A; Relationship of attachment styles and family solidarity with identity in gachsaran's high school pupils.Shiraz: Azad Islamic marvdasht; 2012.

Javaheri F; Hosein zadeh M; Social consequences of GID: social capital and life quality of seekers of sex change in Iran.Journal of Iran social studies. 2011;5(3):3-22.

Saber S, Pasha Sharifi H. [Predicting dimensions of Academic Engagement by Idepentity Style in First Grade girl students of Tehran State High Schools]. Research in Curriculum Planning. 2013; 2(38): 72-85. [Persian]

Nourian N; Doulatshahi B; Rezaei O. Investigation of personality disorders and personality traits in men with gender identity disorder.Journal OURNA of rehabilitation 2008;1(33):55-60.

Javaheri F; kochakian Z; Gender identity disorder and its social factors, to investigate the phenomenon of sexual dissatisfaction in Iran Journal of Social Sciences:Social welfare 2006;21:265-92.

Vasegh rahimparvar F; Mousavi M; Raiesy F; Comparison of life Quality of GID after sex change operation with ordinary women in tehran. Women's journal, midwifery and infertility iran.November 2013;16(47):10-9.

Taheri M; Yaryari F; Serami G; Adib manesh M; Relationship between identity styles, happiness and psychological well-being in university students.Science \& Research in Applied Psychology.Spring 2013;14(1):72-82.

Mojiri M; Review of effectiveness of group therapy with interpersonal approach (based on attachment) on compatibility with gender role, anxiety-depression and self-esteem of men with GID. Mashhad: Ferdowsi University of Mashhad; 2010. 